University of Wollongong

Research Online

Faculty of Engineering and Information

Faculty of Engineering and Information

Sciences - Papers: Part A

Sciences

$1-1-2014$

Design and performance evaluation of a novel magnetorheological valve with a tunable resistance gap

Guoliang $\mathrm{Hu}$

East China JiaoTong University, ghu@uow.edu.au

Ming Long

East China Jiaotong University

Lifan Yu

East China Jiaotong University

Weihua Li

University of Wollongong, weihuali@uow.edu.au

Follow this and additional works at: https://ro.uow.edu.au/eispapers

Part of the Engineering Commons, and the Science and Technology Studies Commons

Research Online is the open access institutional repository for the University of Wollongong. For further information contact the UOW Library: research-pubs@uow.edu.au 


\title{
Design and performance evaluation of a novel magnetorheological valve with a tunable resistance gap
}

\author{
Abstract \\ This paper outlines the design and development of a novel magnetorheological (MR) valve with a tunable \\ resistance gap that varies from $1 \mathrm{~mm}$ to $2 \mathrm{~mm}$ by rotating a valve spool. The finite element modelling and \\ analysis of this proposed MR valve was carried out using ANSYS/Emag software, including achieving the \\ optimal magnetic field distribution and magnetic flux density. A mathematical model of the pressure drop \\ in the MR valve was built to study the pressure drop mechanism while considering the conical annular \\ resistance gap. Moreover, this proposed MR valve with a tunable resistance gap was prototyped and \\ evaluated experimentally, showing that the MR valve has significantly improved its efficiency.

\section{Keywords} \\ MR valve, tunable resistance gap, structure design, pressure drop, finite element analysis

\section{Disciplines} \\ Engineering | Science and Technology Studies

\section{Publication Details} \\ Hu, G., Long, M., Yu, L. \& Li, W. (2014). Design and performance evaluation of a novel magnetorheological \\ valve with a tunable resistance gap. Smart Materials and Structures, 23 (12), 127001-1 - 127001-11.
}




\title{
Design and performance evaluation of a novel magnetorheological valve with a tunable resistance gap
}

\author{
Guoliang $\mathrm{Hu}^{1,}{ }^{*}$, Ming Long ${ }^{1}$, Lifan $\mathrm{Yu}^{1}$ and Weihua $\mathrm{Li}^{2, *}$ \\ ${ }^{1}$ School of Mechantronic Engineering, East China Jiaotong University, Nanchang, Jiangxi Province \\ 330013, China
}

${ }^{2}$ School of Mechanical, Materials and Mechatronic Engineering, University of Wollongong, Wollongong, NSW 2522, Australia

*Author to whom any correspondence should be addressed.

E-mails: glhu@ecjtu.edu.cn,weihuali@uow.edu.au

\begin{abstract}
This paper outlines the design and development of a novel magnetorheological (MR) valve with a tunable resistance gap that varies from $1 \mathrm{~mm}$ to $2 \mathrm{~mm}$ by rotating a valve spool. The finite element modelling and analysis of this proposed MR valve was carried out using ANSYS/Emag software, including achieving the optimal magnetic field distribution and magnetic flux density. A mathematical model of the pressure drop in the MR valve was built to study the pressure drop mechanism while considering the conical annular resistance gap. Moreover, this proposed MR valve with a tunable resistance gap was prototyped and evaluated experimentally, showing that the MR valve has significantly improved its efficiency.
\end{abstract}

\section{Keywords}

MR valve, tunable resistance gap, structure design, pressure drop, finite element analysis

\section{Introduction}

Traditionally, an electro-hydraulic servo control valve is used to achieve fast and accurate control responses such as precise position and speed control applications [1]. However, such a valve is complex, expensive, and has a limited time response, so investigations into alternative actuating mechanisms are constantly being conducted. One such method is to use a magnetorheological fluid (MRF) as a working fluid. MRF is a suspension of micro sized particles dispersed in non-magnetic carrying fluids [2]. It exhibits unusual characteristics in that its rheological properties can be continuously and reversibly changed within milliseconds by applying or removing a magnetic field. This interesting property has inspired the design of a large variety of MRF devices in various engineering applications such as MR valves [3-4], shock absorbers and dampers [5-6], engine mounts, and clutch systems [7-8]. Of these devices the MR valve is generally used to control the speed of the hydraulic actuator of MRF because it has many advantages, including: valves with no moving parts, the complexity and durability issues in conventional mechanical control valves is removed, and a direct transduction from an electrical control signal to a change in mechanical properties is provided [9-10].

In recent years the research of MR valves aims at achieving large pressure drops or fast responses by either designing a novel structure or optimising an existing structure. Rosenfield and Wereley [11] proposed an analytical optimisation design method for MR valves and dampers based 
on the assumption of a constant magnetic flux density throughout the magnetic circuit to ensure that one region of the magnetic circuit does not become prematurely saturated and cause a bottleneck. Nguyen and Choi [12-14] presented a geometric optimal design of MR valves constrained in a specific volume using the finite element method to improve the pressure drop in valves. Salloom et al. [15] developed a new type of MR valve where the valve coil was outside the effective area of the MR fluid. The simulation results showed that the efficiency of the proposed MR valve was superior to those with one coil annular fluid flow resistance channels and with two coils annular fluid flow resistance channels simultaneously. Salloom [16-17] also proposed an MR proportional directional control valve (4/3 MR valve), which was evaluated experimentally. Yoo et al. [18-20] developed a design that maximised performance while minimising the volume and mass consumption of the valve from the fluid mechanics purpose. They also constructed a hydraulic actuation system using four MR valves that were configured like a Wheatstone bridge. Hu et al. [21-22] designed an energy absorber using an MR bypass valve filled with ferromagnetic beads, with the results showing that it can provide a high controllable damping force over a wide force range. Gordaninejad et al. [23-24] developed a large-scale modular MRF bypass damper with a two-stage disk type bypass MR valve which can provide a pressure drop of over 9.0 MPa. Gordaninejad also compared the response times of the MR valve with the annular flow and radial flow geometries. Wang and Ai [25-26] proposed a novel MR valve with annular flow and radial flow resistance gaps, and the results showed that the radial fluid flow gaps in the MR valve were more efficient in providing a larger controllable range than those with annular fluid flow gaps. Imaduddin and Mazlan [27-28] also developed a compact MR valve with multiple annular and radial gaps. The simulation and experimental results revealed that this design could increase the achievable pressure drop of the valve by more than $2.5 \mathrm{MPa}$. Our group presented an efficient double coil MR valve with evaluated simulations and experimental

verifications [29-30]. We also optimised the design of a very efficient MR valve using finite element analysis with a maximum block pressure over $1900 \mathrm{KPa}$ [31].

However, the resistance gaps of all these MR valves mentioned above were all fixed, which hindered the maximum resistance forces in the gap to some extent. In order to increase the fluid flow resistance force of MR valves, the resistance gap has to be decreased and the energy consumption would be increased for conventional MR valves with either an annular flow direction or a radial fluid flow direction or both directions. However, the smaller resistance gap would lead to the risk of the valve blocking. An alternative approach in enlarging the maximum resistance force is to increase the length of the resistance gap, but this method makes it difficult to miniaturise MR valves. Therefore, in this study, we proposed a new MR valve with tunable resistance gaps from $1 \mathrm{~mm}$ to $2 \mathrm{~mm}$. It is expected that the new design will significantly enhance the operating ranges of MR valves as the MR valve at each selected gap can operate as a conventional MR valve. Specifically, the valve performance, especially the pressure drop between the inlet port and the outlet port of the valve, was investigated through theoretical analysis, simulation evaluation and experiment verification.

\section{Design and development of a MR valve with a tunable resistance gap}

\subsection{Structure analysis of the MR valve with a tunable resistance gap}

The structure of the MR valve with a tunable resistance gap is shown in figure 1; it consists of a valve spool, lock nut, exciting coil, valve sleeve, valve body, and end covers. The exciting coil was wound onto the valve spool and protruded out through a hole in the valve body. The gaps between 
the valve spool and valve sleeve could be changed by rotating the valve spool; that means the thickness of the resistance gap could also be tuned. In this design, the left part of the valve spool was drilled two holes; a hex wrench was inserted into the hole to rotate the valve spool. As the left part of the valve spool and the left end cover was connected with a screw thread, and the right part of the valve spool was supported by the right end cover, the valve spool can rotate along the axial direction when turning the hex wrench. In addition, a lock nut is used in the left part of the end cover to prevent any axial movement of the valve spool when the resistance gap is confirmed.

Figure $2 \mathrm{a}$ and $\mathrm{b}$ show the two extreme working states, i.e., the minimum and the maximum workings states, of the proposed MR valve, respectively. As shown in Figure 2(a), when the valve spool protruding out of the cover on the right side is at its maximum state, that is, $l$ equals $l_{\max }$, the resistance gap between the valve spool and the valve sleeve can reach its minimum value of $1 \mathrm{~mm}$, i.e., $h_{\mathrm{min}}=1 \mathrm{~mm}$. As shown in Figure 2(b), when the valve spool protruding from the cover on the right side is at its minimum state, that is, $l$ equals $l_{\text {min }}$, the resistance gap between the valve spool and the valve sleeve can reach its maximum value of $2 \mathrm{~mm}$, i.e., $h_{\max }=2 \mathrm{~mm}$.

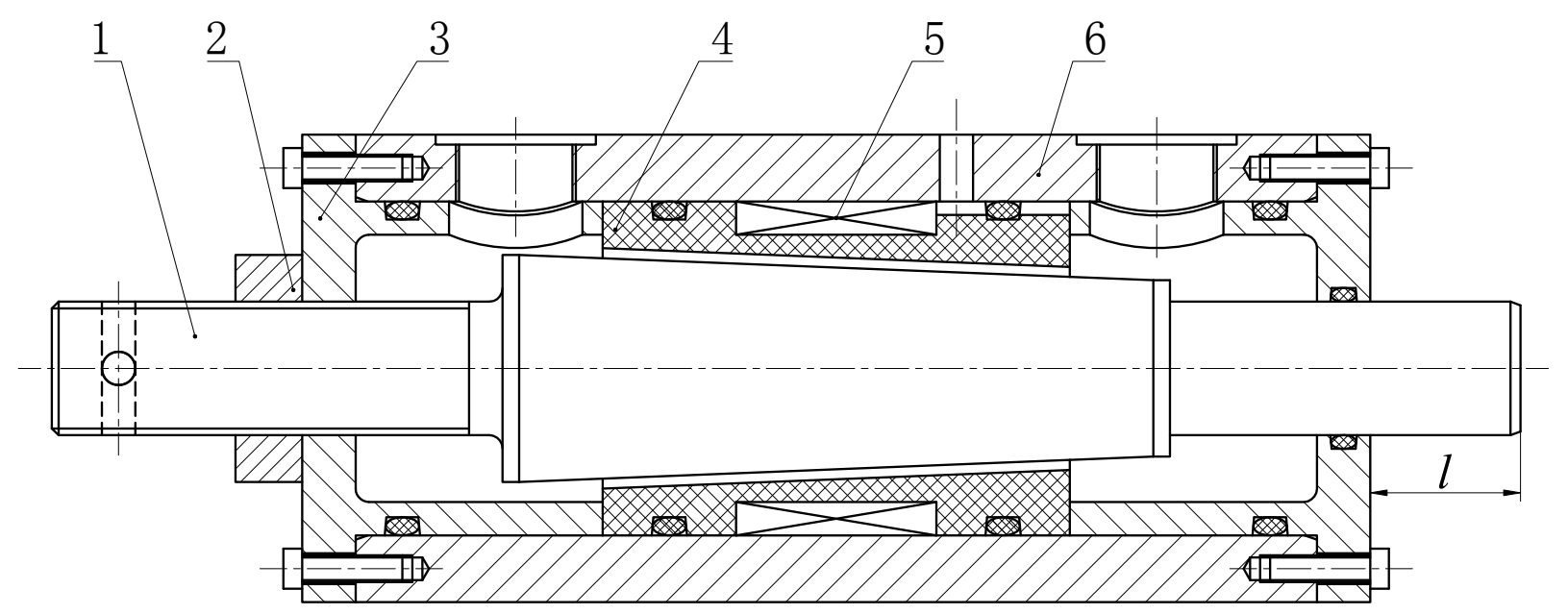

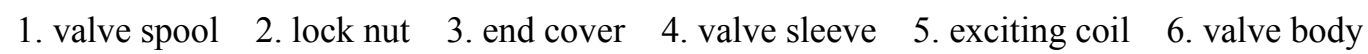

Figure 1. Schematic diagram of the MR valve with a tunable resistance gap

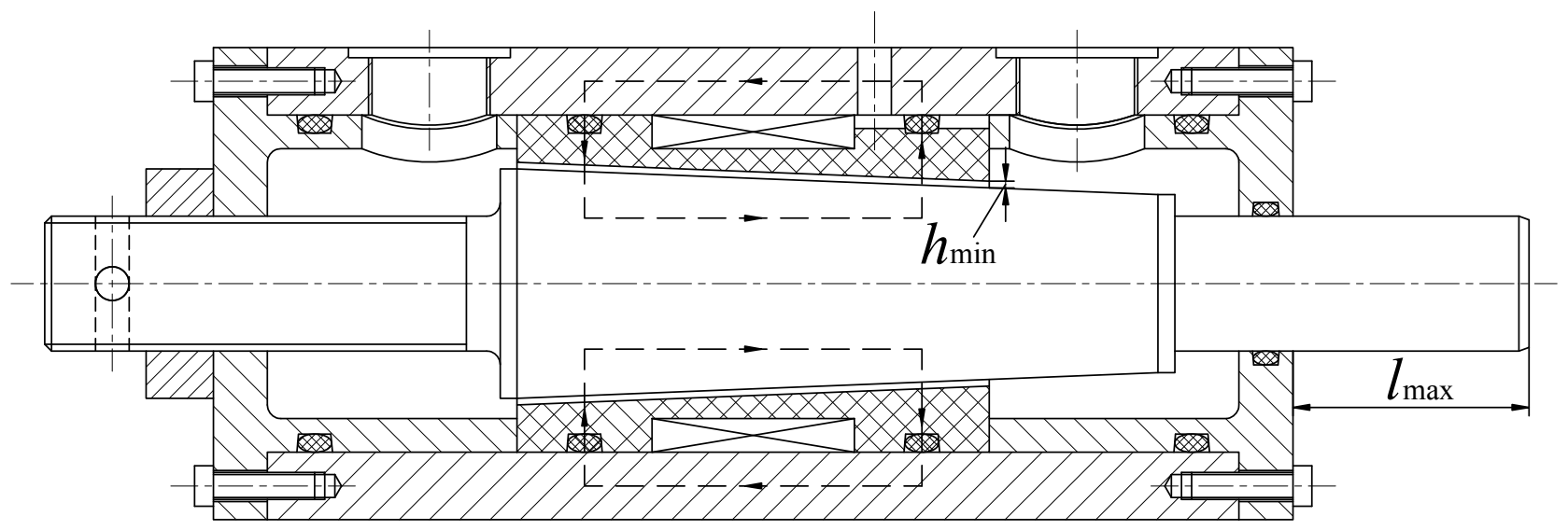

(a) 


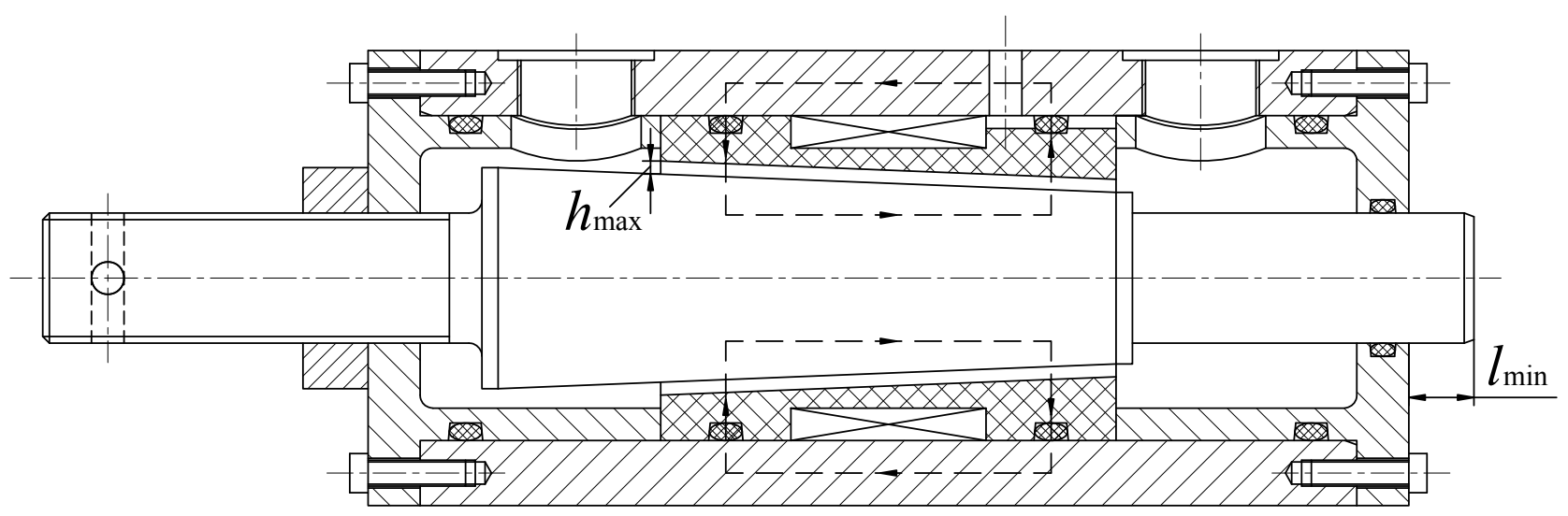

(b)

Figure 2. Schematic diagrams of the minimum working state and the maximum working state of the MR valve with a tunable resistance gap: (a) the minimum resistance gap, and (b) the maximum resistance gap

The resistance gap $h$ can be expressed as

$$
h=h_{\text {min }}+\left(l_{\text {max }}-l\right) \times \tan \theta \times \cos \theta \approx h_{\text {min }}+\left(l_{\text {max }}-l\right) \times \theta
$$

where $h_{\min }$ is the minimum thickness of the resistance gap, $l$ is the length of the valve spool protruding from the cover on the right side, $l_{\max }$ is the length of the valve spool protruding from the cover on the right side when the resistance gap is minimum, and $\theta$ is the half cone angle of the valve spool, as shown in Figure 3.

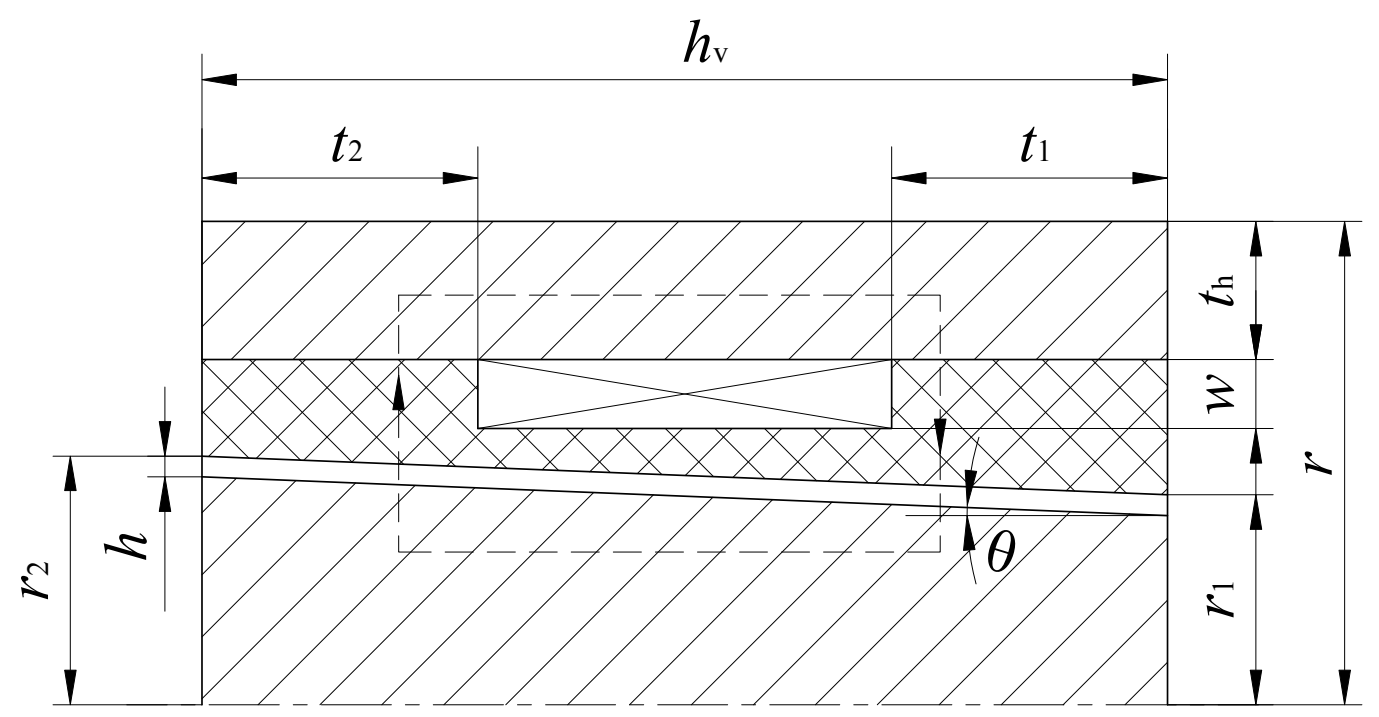

Figure 3. Key dimensions of the MR valve with a tunable resistance gap

It can be seen that the resistance gap is inversely proportional to the length of the valve spool that protrudes from the cover on the right side from Figure 2 and equation (1), so the resistance gap can be tuned by rotating the valve spool. After determining the resistance gap thickness, a constant direct current is applied to the exciting coil and closed loop magnetic circuits will be generated in the valve body, valve sleeve, the resistance gap and valve spool, while simultaneously intense magnetic fields will generate in the resistance gap that are basically perpendicular to the gap. Finally, a pressure drop between the inlet port and the outlet port of the MR valve will be produced because of the shear stress in the resistance gap. Therefore by adjusting the direct current and the locations of the valve spool, this pressure drop can be controlled. 


\subsection{Magnetic circuit of the MR valve with a tunable resistance gap}

A magnetic flux is needed to induce changes in the viscosity of the MR fluid, so the magnetic field applied to the MR fluid has to be predicted accurately by analysing the magnetic circuit which serves as the "supply line" of magnetic flux to the MR fluid.

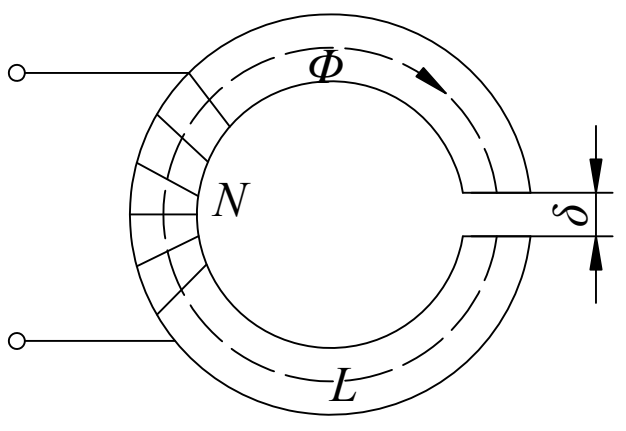

(a)

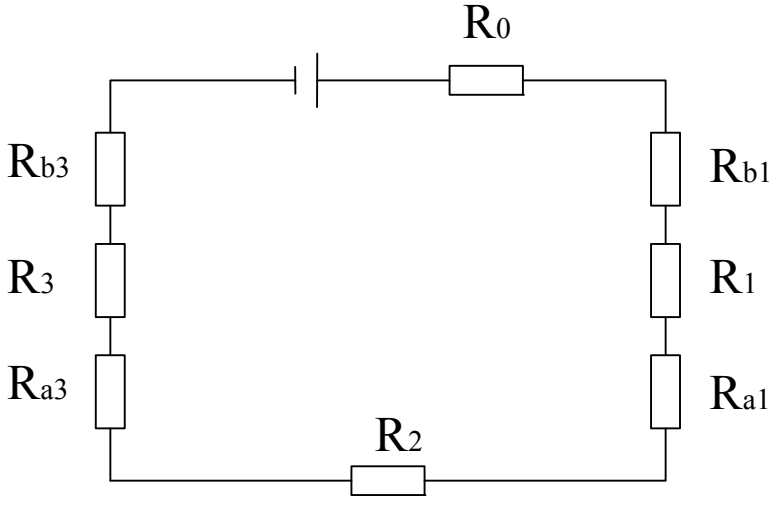

(b)

Figure 4. Magnetic circuit of the MR valve: (a) the simplified magnetic circuit, and (b) the equivalent magnetic circuit model

Figure 4 shows the simplified and equivalent magnetic circuit of the MR valve with the tunable resistance gap. In the figure 4(a), $\delta$ is length of the air gap, and $L$ is centre line circumference of the magnetic core.

According to the principle of the continuity of magnetic flux to determine the magnetic flux density throughout its conduit, consider

$$
\phi_{\mathrm{MRF}}=\phi_{\text {steel }}=\phi
$$

where $\phi_{\mathrm{MRF}}$ and $\phi_{\text {steel }}$ are the magnetic flux density of the MR fluid and the valve housing in the primary magnetic path, respectively.

The magnetic circuit is analysed using Ohm's law as follows

$$
N I=\phi\left(R_{0}+R_{1}+R_{a 1}+R_{b 1}+R_{2}+R_{3}+R_{a 3}+R_{b 3}\right)
$$

where $N$ is the number of turns of the exciting coil, $I$ is the applied direct current, $R_{0}$ is the magnetic resistance of valve body, $R_{1}$ is the magnetic resistance of the MRF at the right hand side, $R_{\mathrm{a} 1}$ is the magnetic resistance of the valve spool at the right flange, $R_{\mathrm{b} 1}$ is the magnetic resistance of the valve sleeve at the right flange, $R_{2}$ is the magnetic resistance of the valve spool at the horizontal segment, $R_{3}$ is the magnetic resistance of the MRF at the left hand side, $R_{\mathrm{a} 3}$ is the magnetic resistance of the valve spool at the left flange, and $R_{\mathrm{b} 3}$ is the magnetic resistance of the valve sleeve at the left flange.

The magnetic resistance of the valve body is $[3,32]$

$$
R_{0}=\frac{H-0.5\left(t_{1}+t_{2}\right)}{\pi\left[r^{2}-\left(r-t_{h}\right)^{2}\right] \mu_{1}}
$$

where $\mu_{1}$ is the relative magnetic permeability of the steel material of the valve body.

The magnetic resistance of the valve spool and the valve sleeve at the right flange can be approximately added by 


$$
R_{a 1}+R_{b 1}=\frac{r-t_{h}}{\pi\left(r-t_{h}\right) t_{1} \mu_{1}}
$$

The magnetic resistance of the MRF at the right hand side is

$$
R_{1}=\frac{h}{2 \pi\left(r_{1}+0.5 h+0.5 t_{1} \times \tan \theta\right) t_{1} \mu_{2}}
$$

where $\mu_{2}$ is the relative magnetic permeability of the MRF at the right hand.

The magnetic resistance of the valve spool at the horizontal segment can be expressed as

$$
R_{2}=\frac{H-0.5\left(t_{1}+t_{2}\right)}{\mu_{1} \frac{V}{H-0.5\left(t_{1}+t_{2}\right)}}
$$

where $V$ is the effective volume of the valve spool.

The magnetic resistance of the valve spool and the valve sleeve at the left flange can be approximately added by

$$
R_{a 3}+R_{b 3}=\frac{r-t_{h}}{\pi\left(r-t_{h}\right) t_{2} \mu_{1}}
$$

The magnetic resistance of the MRF at the left hand side is

$$
R_{3}=\frac{h}{2 \pi\left(r_{2}-0.5 h-0.5 t_{2} \tan \theta\right) t_{2} \mu_{3}}
$$

where $\mu_{3}$ is the relative magnetic permeability of the MRF at the left hand.

By substituting equations (4)-(9) into equation (3), the magnetic flux density can be obtained.

\subsection{Magnetic properties of MR fluid and steel used in the proposed MR valve}

The MR fluid provided by the Chongqing Instrument Material Research Institute in China was used in the following simulations and experiments. Table 1 summarises the performance index of the MR fluid. Its field dependent properties are shown in Figure 5.

Table 1. Performance index of MR fluid with MRF-J01T

\begin{tabular}{cc}
\hline Project & Parameters \\
\hline mass density & $2.65 \mathrm{~g} / \mathrm{cm}^{3}$ \\
viscosity without magnetic field & \\
$\left(\gamma=10 / \mathrm{s}, 20{ }^{\circ} \mathrm{C}\right)$ & $0.8 \mathrm{~Pa} \cdot \mathrm{s}$ \\
shear stress $(5000 \mathrm{Gs})$ & $>50 \mathrm{KPa}$ \\
operational temperature range & $-40 \sim 130{ }^{\circ} \mathrm{C}$ \\
\hline
\end{tabular}




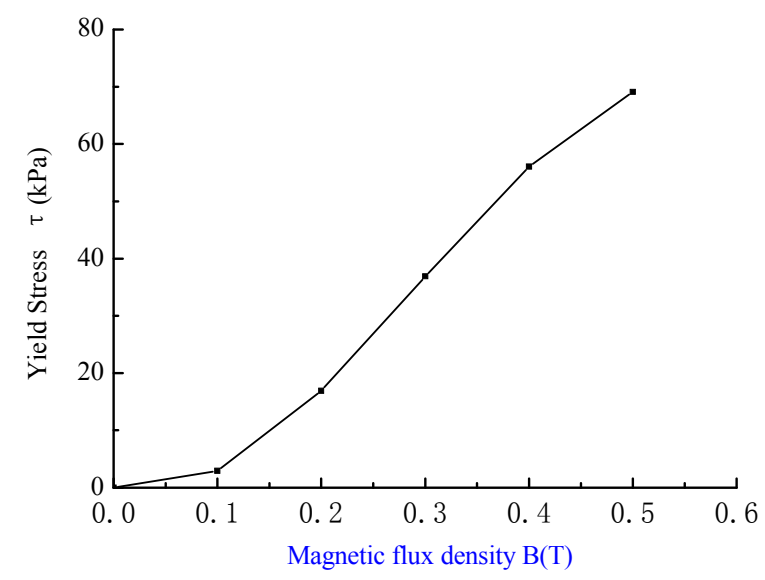

(a)

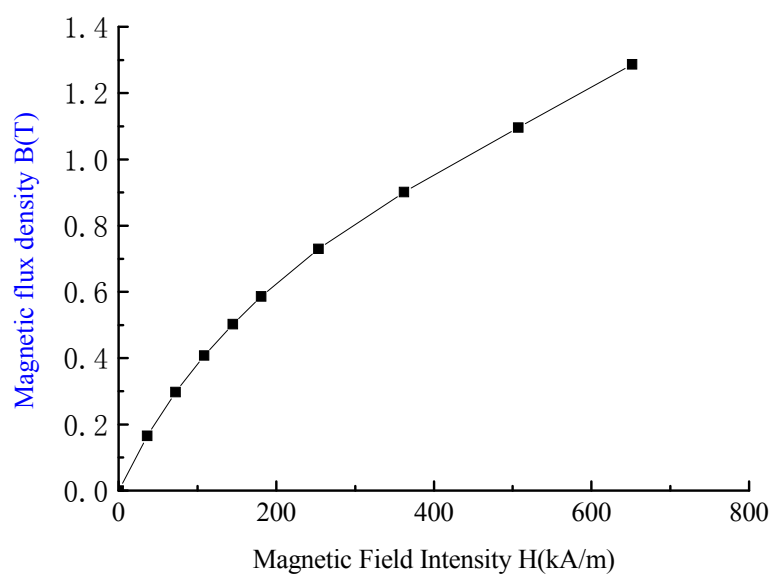

(b)

Figure 5.Specification of the MR fluid type MRF-J01T: (a) the variation of the yield stress $\tau$ and the magnetic flux density $B$, and (b) the variation of the magnetic flux density $B$ and the magnetic field intensity $\mathrm{H}$.

By observing Figure 5(a), the $\tau-B$ relationship using the least square method to cubic polynomial fitting of MRF-J01T can be represented as:

$$
\tau_{y}=a_{1} \times B^{3}+a_{2} \times B^{2}+a_{3} \times B+a_{4}
$$

where $\alpha_{1}=-984.2742 \mathrm{kPa} / \mathrm{T}^{3}, \alpha_{2}=865.3901 \mathrm{kPa} / \mathrm{T}^{2}, \alpha_{3}=-48.4644 \mathrm{kPa} / \mathrm{T}, \alpha_{4}=0.0182 \mathrm{kPa}$.

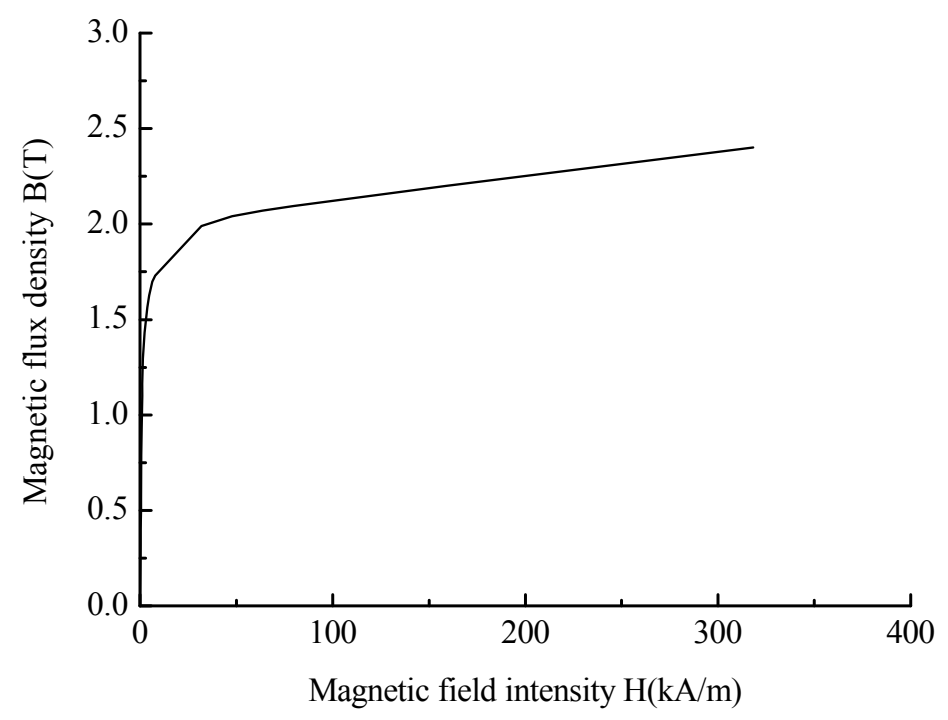

Figure 6. B-H curve of steel material (No. 10)

Figure 6 shows the density of magnetic flux versus the strength of the magnetic field of the steel material (No. 10) used in the valve's body, sleeve, and spool, respectively.

\subsection{Simulation analysis using the FEM method}

Figure 7 shows the axisymmetric two dimensional finite element model of the proposed MR valve using ANSYS/EMAG software. The MR valve consists of the body, the sleeve, the exciting coil, the spool and the resistance gap. The spool, sleeve, and body were made from No. 10 steel whose permeability is defined by the B-H curve of No. 10 steel, as shown in Figure 6. The exciting coil is copper with a relative permeability of 1 . The resistance gap is full of MR fluid whose permeability is defined by the B-H curve of MRF-J01T, as shown in Figure 5(b). In the simulation, the resistance 
gap that the MR fluid passes through was divided into three segments, that is, the left resistance gap, the middle resistance gap and the right resistance gap. The current density in the exciting coil was set at $2.5 \mathrm{~A} / \mathrm{mm}^{2}$, the diameter of the exciting coil is $0.6 \mathrm{~mm}$, and the number of the turns is 284 .

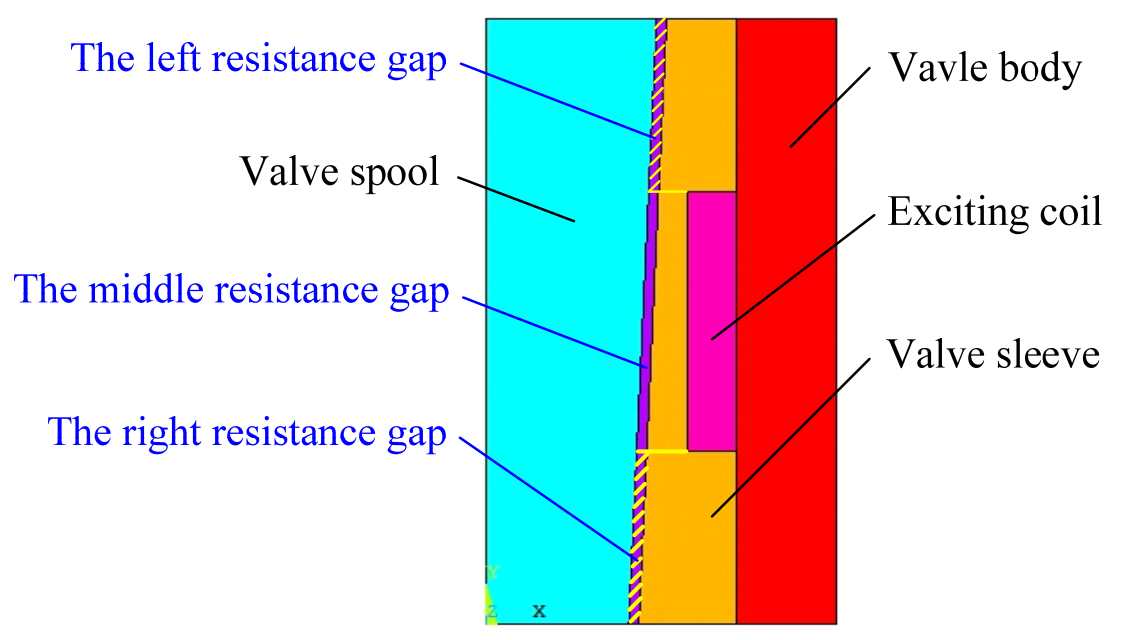

Figure 7. Two-dimensional finite element model of the MR valve with three segment resistance gap

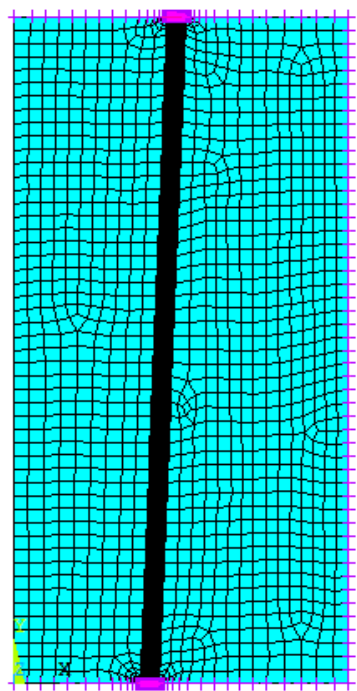

Figure 8. The meshing model of the MR valve with a tunable resistance gap

Figure 8 shows the meshing model of the MR valve with the tunable resistance gap, which was constructed using the smart meshing tool and has a smart size of 1 .

Figure 9 shows the finite element analysis results of the proposed MR valve when a simulated direct current of 1A was applied and the resistance gap was $1 \mathrm{~mm}$.

Figure 9(a) shows the magnetic flux density contour of the proposed MR valve. As shown in figure 9(a), the magnetic flux densities at the left resistance gap and the right resistance gap are far greater than that of the middle resistance gap, and the magnetic flux density at the middle resistance gap is nearly zero, which means that most of the magnetic flux lines pass through the valve sleeve.

Figure 9(b) shows the distribution of the magnetic flux line and the defined paths, where path $\mathrm{S}_{1}$ is in the left resistance gap, and path $\mathrm{S}_{2}$ is in the right resistance gap. It can be seen that the magnetic flux lines in the proposed MR valve were mainly distributed along the path of primary magnetic flux, which is consistent with an ideal case. However, some magnetic flux lines still formed a closed magnetic field inside the sleeve because the permeability of No. 10 steel is larger than that of MR fluid.

Figure 9(c) shows the magnetic flux densities at the left resistance gap along the path $\mathrm{S}_{1}$. There 
are two magnetic flux densities in the figure, one is the magnetic flux density $\mathrm{BX}$ along the $\mathrm{X}$ direction and the other is the magnetic flux density BY along the $\mathrm{Y}$ direction, which is different from the conventional MR valves as they are only one magnetic flux density along $\mathrm{X}$ direction or $\mathrm{Y}$ direction separately. It can also be seen that the magnetic flux density BX is far greater than the magnetic flux density BY, the reason of which is that the half cone angle $\theta$ is very small.

Figure $9(\mathrm{~d})$ shows the magnetic flux densities at the right resistance gap along the path $\mathrm{S}_{2}$. Similarly, the magnetic flux density BX is far greater than the magnetic flux density BY too. The reluctance at the left resistance gap was larger than that of the right resistance gap because the radial diameters of the resistance gap were gradually reduced, thus the magnetic fields at the left resistance gap were more intense than those at the right resistance gap.

In the simulations, the magnetic flux density $\mathrm{BX}$ in the $\mathrm{X}$ direction and the magnetic flux density BY in the Y direction could be obtained using ANSYS/Emag software. However, the fluid flow direction in the resistance gap is not parallel to the $\mathrm{X}$ direction due to the cone angle $\theta$ of the valve spool. In order to investigate the fluid flow conditions in the resistance gap, the coordinate transformation was carried out using the following expressions

$$
\begin{aligned}
& B_{/ /}=B X \cos \theta+B Y \sin \theta \\
& B_{\perp}=B X \sin \theta+B Y \cos \theta
\end{aligned}
$$

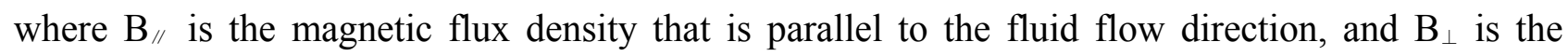
magnetic flux density that is perpendicular to the fluid flow direction.

Figure 9(e) and 9(f) show the magnetic flux densities $\mathrm{B}_{/ /}$and $\mathrm{B}_{\perp}$ at the left resistance gap and the right resistance gap, respectively. As shown in both figures, the magnetic flux densities $\mathrm{B}_{\perp}$ basically equal zero, which coincides with the requirements of the proposed MR valve for the directions of the magnetic flux density. Furthermore, the magnetic flux densities $B_{/ /}$at the left resistance gap is about $0.47 \mathrm{~T}$, while the magnetic flux densities $\mathrm{B}_{/ /}$at the right resistance gap is about $-0.44 \mathrm{~T}$, which is because that the reluctance at the left resistance gap is larger than that of the right resistance gap.

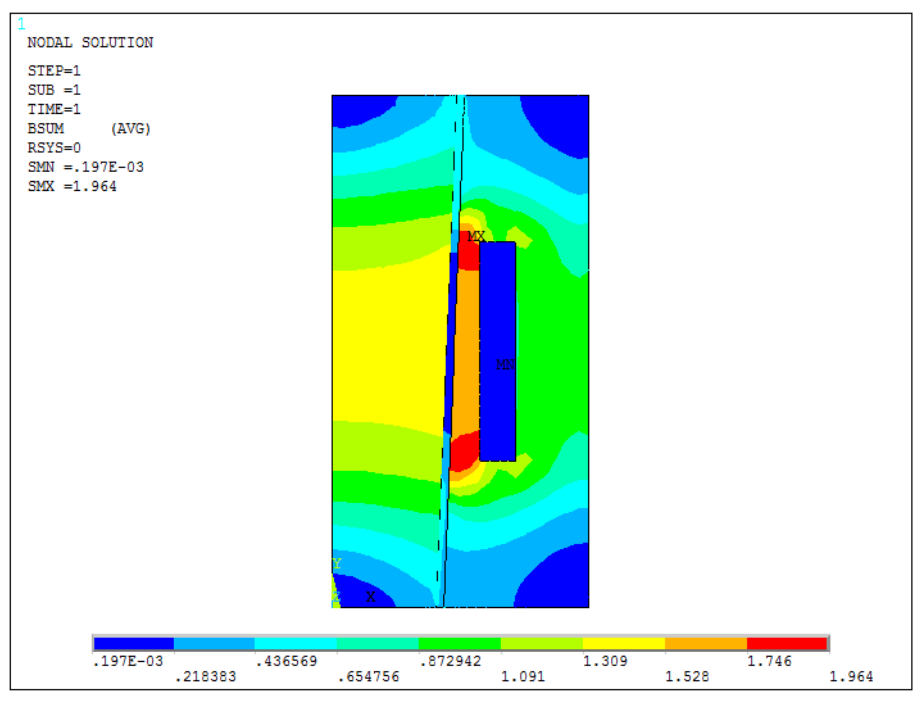

(a)

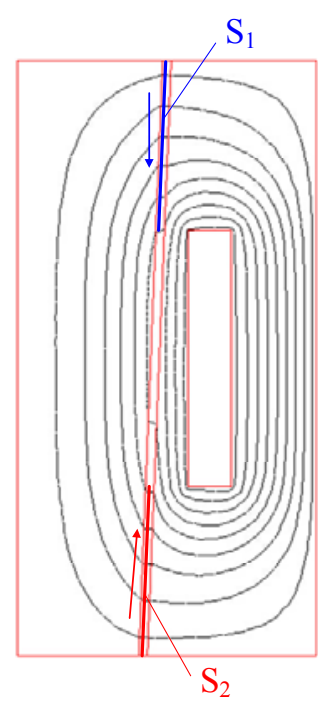

(b) 


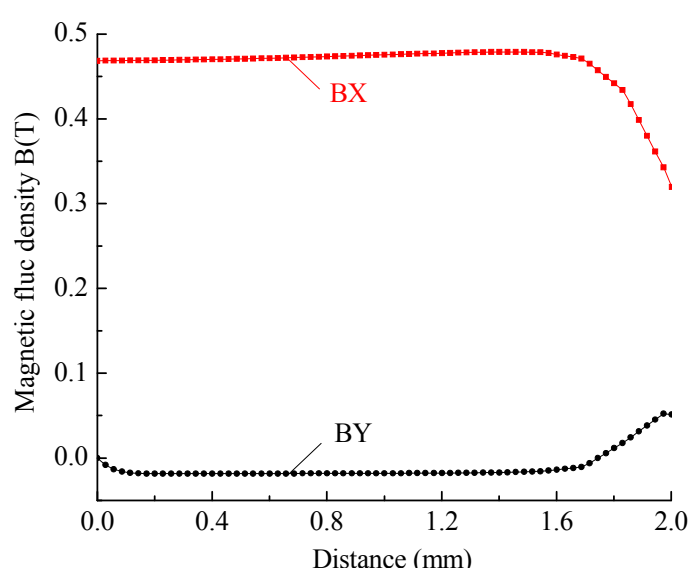

(c)

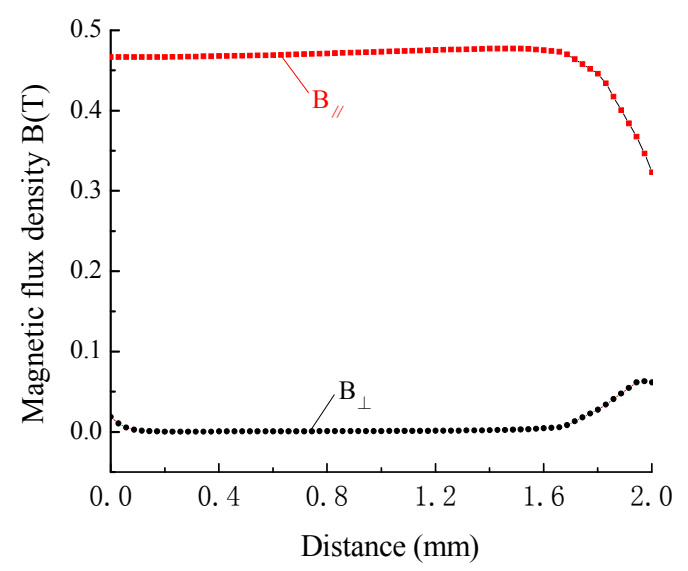

(e)

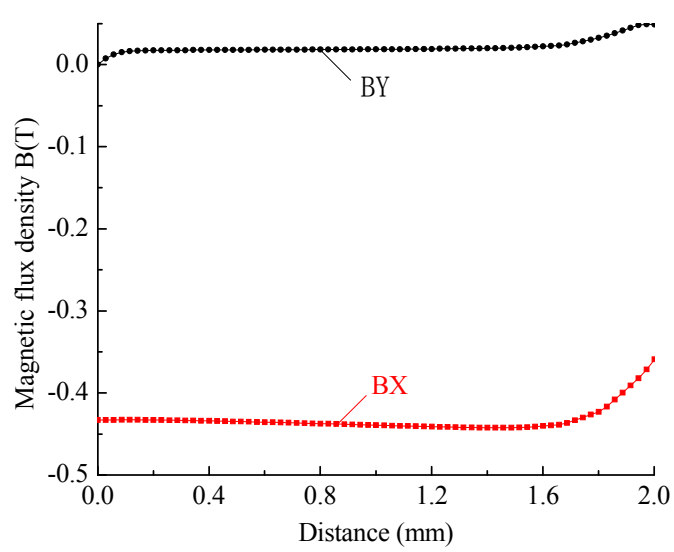

(d)

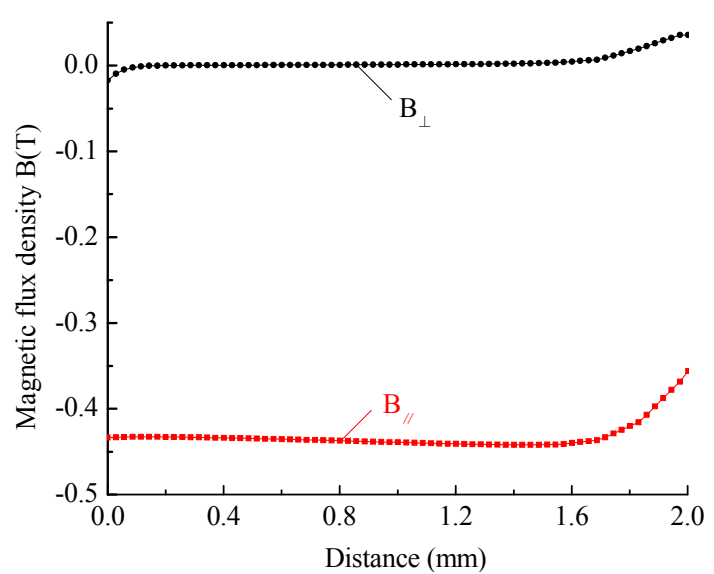

(f)

Figure 9. Simulations of MR valve when $I=1 \mathrm{~A}$ and $h=1 \mathrm{~mm}$ : (a) the contours of magnetic field density, (b) distribution of the magnetic flux line and the defined paths along the fluid flow direction, (c) magnetic flux densities BX and BY at the left resistance gap, (d) magnetic flux densities BX and $\mathrm{BY}$ at the right resistance gap, (e) magnetic flux densities $\mathrm{B}_{\perp}$ and $\mathrm{B}_{/ /}$at the left resistance gap, (f) magnetic flux densities $\mathrm{B}_{\perp}$ and $\mathrm{B}_{/ /}$at the left resistance gap.

Figure 10 shows the relationships among the magnetic flux density at the left resistance gap, the applied currents and the thicknesses of the resistance gap in the longitudinal direction. Figure 11 shows the relationships among the magnetic flux density at the right resistance gap, the applied currents and the thicknesses of the resistance gap in the longitudinal direction. Both figures show that when the resistance gap was fixed, the magnetic flux density increased as the applied current increased, but decreased as the resistance gap increased in the longitudinal direction. This occurred because the magnetic resistance of the spool and the resistance gap increased as the resistance gap became wider, which in turn led to a decrease in the magnetic flux density.

Figure 12 shows the pressure drop between the inlet port and the outlet port of the proposed MR valve under different applied currents. This pressure drop was derived from the equations (10) and (15) considering the coefficients of the magnetic flux leakage and the magnetic fields changes due to uneven flow in the resistance gap. In the simulations, the system flow rate is $4 \mathrm{~L} / \mathrm{min}$, the coefficient of the magnetic flux leakage is 0.7 , and the coefficient of the magnetic fields changes is 0.64. As shown in Figure 12, this pressure drop increased as the applied current increased and the resistance gap decreased in the longitudinal direction; a result that was similar to the changes in the magnetic flux density shown in Figures 10 and 11. The maximum pressure drop was about 1800 $\mathrm{KPa}$ when the resistance gap was $1 \mathrm{~mm}$ wide. 


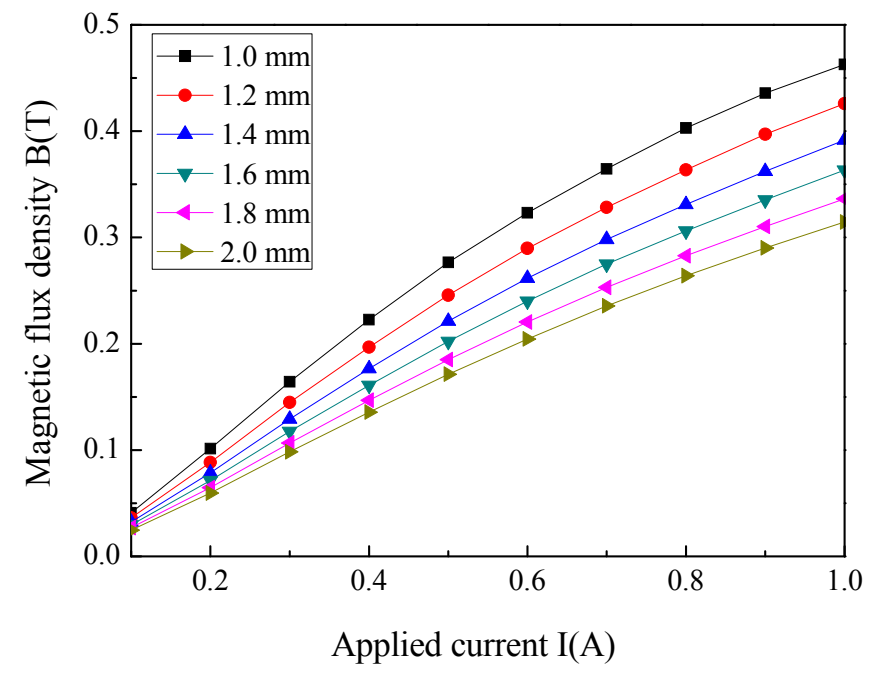

Figure 10. Simulations of the magnetic flux density at the left resistance gap under different applied currents

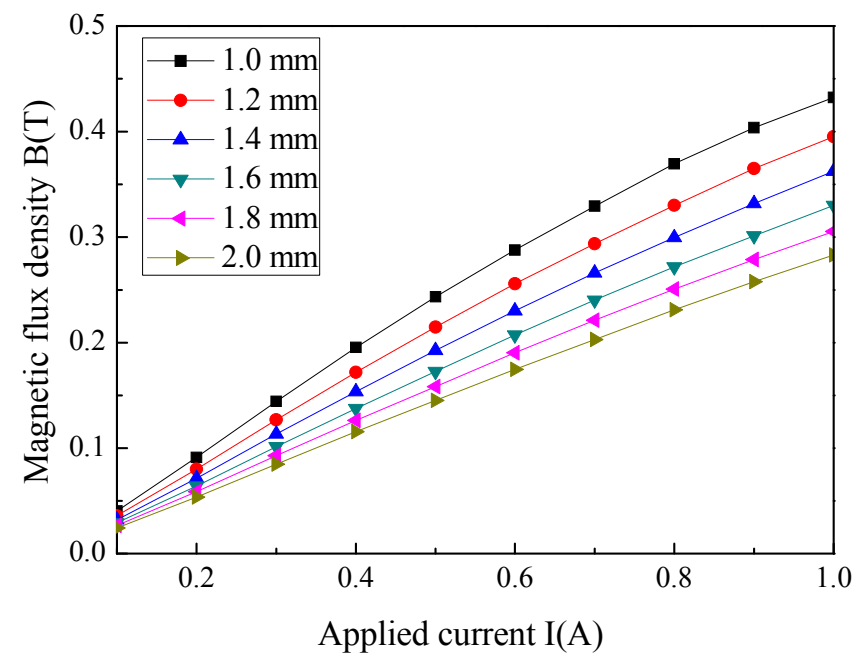

Figure 11. Simulations of the magnetic flux density at the right resistance gap under different applied currents

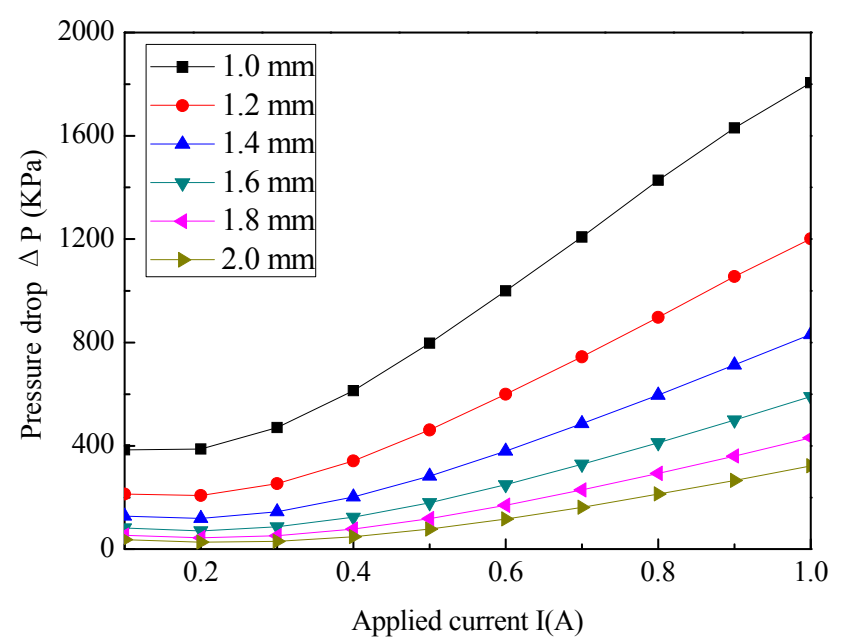

Figure 12. Simulations of the pressure drop under different applied currents ( $q=4 \mathrm{~L} / \mathrm{min})$ 


\subsection{Prototyping of the MR valve with a tunable resistance gap}

Figure 13 shows the prototype of the proposed MR valve with the tunable resistance gap. Table 2 summarises the primary parameters of the proposed MR valve.



(a)

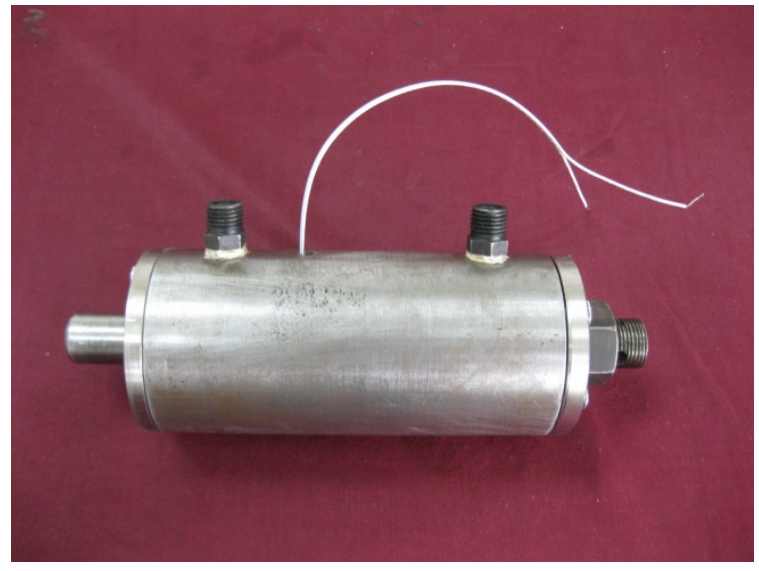

(b)

Figure 13. Photograph of the proposed MR valve: (a) valve parts, and (b) valve assembly

Table 2. Primary parameters of the MR valve with a tunable resistance gap

\begin{tabular}{l|c}
\hline \multicolumn{1}{c|}{ Parameters } & Values (mm) \\
\hline valve core length $h_{\mathrm{v}}$ & 70 \\
the left hand length of valve sleeve $t_{2}$ & 20 \\
the right hand length of valve sleeve $t_{1}$ & 20 \\
the large end radius of valve sleeve $r_{2}$ & 18 \\
the small end radius of valve sleeve $r_{1}$ & 15.2 \\
winding thickness $w$ & 5 \\
valve body thickness $t_{\mathrm{h}}$ & 10 \\
MF valve radius $r$ & 35 \\
\hline
\end{tabular}

\section{Analysis of the pressure drop of the MR valve with a tunable resistance gap}

\subsection{Mathematic modeling}

The fluid flow channel of the proposed MR valve is a typical conical annular resistance gap, from which an annual conical model can be established from the parallel disk model based on the hypothesis that the extended surface of the conical annular resistance gap is equivalent to part of a parallel disk gap. Figure 14 shows the working model of the MR fluids in the conical annular fluid flow resistance gap, where the central angle $\alpha$ of the extended surface equals $2 \pi \sin \theta$.

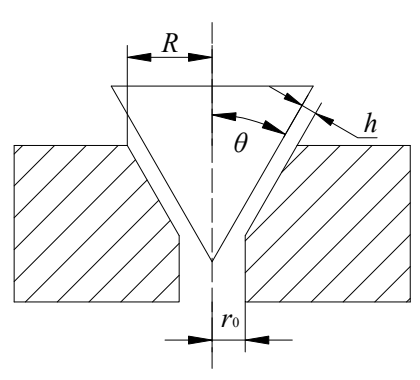

(a)

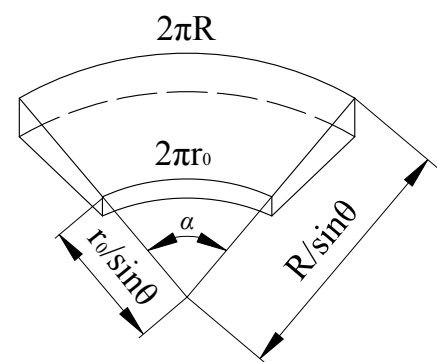

(b)

Figure 14. Modelling of the fluid flow in the conical annular resistance gap: (a) sectional view, and (b) extended surface 
The pressure drop $\triangle P$ of the MR valve in the conical annular resistance gap consists of a viscous pressure drop $\triangle P_{\eta}$ and a field-dependent pressure drop $\triangle P_{\tau}$. It is approximated as

$$
\Delta P=\Delta P_{\eta}+\Delta P_{\tau}
$$

The viscous pressure drop $\triangle P_{\eta}$ is given by

$$
\Delta P_{\eta}=\frac{6 \eta q}{\pi \sin \theta h^{3}} \ln \frac{r_{2}}{r_{1}}
$$

where $\eta$ is the fluid viscosity without an applied magnetic field, and $q$ is the volumetric flow rate.

The field-dependent pressure drop $\triangle P_{\tau}$ is defined as

$$
\Delta P_{\tau}=\Delta P_{\tau 1}+\Delta P_{\tau 2}+\Delta P_{\tau 3}
$$

where $\triangle P_{\tau 1}$ is the field-dependent pressure drop produced in the left resistance gap, $\triangle P_{\tau 2}$ is the field-dependent pressure drop produced in the middle resistance gap, and $\triangle P_{\tau 3}$ is the field-dependent pressure drop produced in the right resistance gap.

As Figures 9(a) and 9(b) show, the magnetic flux line did not pass through the middle resistance gap, the magnetic flux density in this region was about zero, and the field-dependent pressure drop $\triangle P_{\tau 2}$ was zero too. So the field-dependent pressure drop $\triangle P_{\tau}$ was deduced as

$$
\Delta P_{\tau}=\frac{c_{2} \tau_{y}}{h} \frac{t_{2}}{\cos \theta}+\frac{c_{1} \tau_{y}}{h} \frac{t_{1}}{\cos \theta}
$$

where $\tau_{\mathrm{y}}$ is the dynamic yield stress in response to an applied magnetic field, and $c_{1}$ and $c_{2}$ are the modified coefficients.

By substituting equations (14) and (16) into equation (13), the pressure drop $\triangle P$ of the proposed MR valve is

$$
\Delta P=\frac{6 \eta q}{\pi \sin \theta h^{3}} \ln \frac{r_{2}}{r_{1}}+\frac{c_{2} \tau_{y}}{h} \frac{t_{2}}{\cos \theta}+\frac{c_{1} \tau_{y}}{h} \frac{t_{1}}{\cos \theta}
$$

\subsection{Experimental test rig setup}

An experimental test rig, shown in Figure 15, was built to validate the performance of this proposed MR valve. A motor driven fixed gear pump was used as a power unit, two pressure transducers a and $\mathrm{b}$ were used to measure pressure at the inlet port and outlet port respectively. A relief valve (a) was used as a safety valve to protect the hydraulic system, and a relief valve (b) was used to simulate the loading cases. A DC power (a) was used to supply power to the two pressure transducers, and it was used in (b) to supply power for the exciting coil of the proposed MR valve. A data acquisition board was used to capture the pressures. A host computer was used to monitor the relevant test parameters of the hydraulic system in real time. In the proposed MR valve, the diameter of the exciting coil is $0.6 \mathrm{~mm}$, and the number of the turns is 284 . 


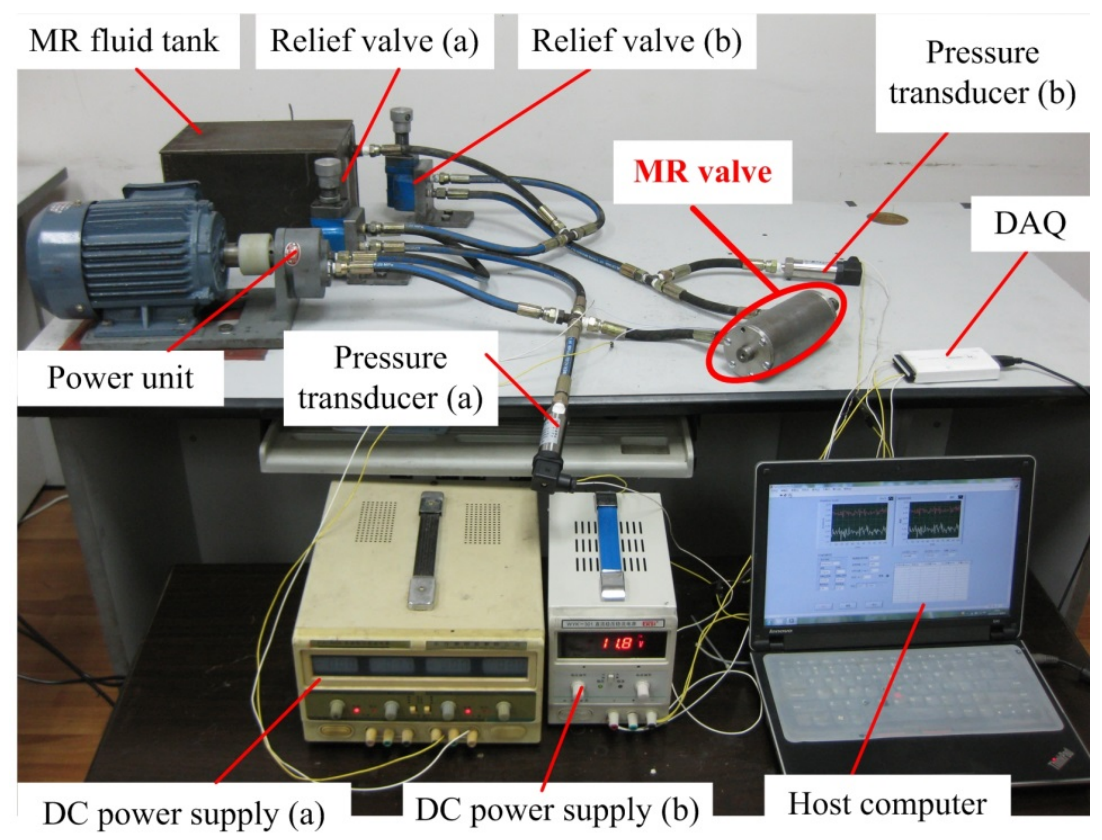

Figure 15. Experimental test rig of the proposed MR valve

\subsection{Experimental results analysis}

\subsubsection{Effect of width of resistance gap on the pressure drop}

Figure 16 shows the pressure conditions of MR valve under continuously applied currents when the resistance gaps were $1.0 \mathrm{~mm}$ and $2.0 \mathrm{~mm}$ wide, respectively. Here the inlet port pressure and pressure drop at the same width of resistance gap increased as the applied currents increased, while the outlet port pressure remained basically unchanged because the pressure drop equals a subtraction of the inlet port and outlet port pressures, while the outlet port pressure was held at a certain value by the relief valve (b) in Figure 15. However, the outlet port pressure fluctuated a little because the gears in the fixed gear pump were worn out due to long operating time and the abrasive nature of MR fluid.

Figure 17 shows the pressure drop of the MR valve under different applied currents. This pressure drop increased as the applied current increased, while this pressure drop also increased as the resistance gap decreased in the longitudinal direction; a similar result to the simulations shown in Figure 12. The maximum pressure drop was about $1150 \mathrm{KPa}$ when the applied current was $1.8 \mathrm{~A}$ and the resistance gap was $1 \mathrm{~mm}$ wide, and the simulation was $1800 \mathrm{KPa}$ in the same case. The deviation between the simulation and the experiments was probably because the MR fluid decreased in performance under long operating time and the internal diameter of the MR valve increased due to the abrasive nature of MR fluid.

Figure 18 shows the regulating scope of the proposed MR valve. When the resistance gap was set the minimum value of $1 \mathrm{~mm}$, the pressure drop can be tuned from $250 \mathrm{KPa}$ to $1150 \mathrm{KPa}$. While when the resistance gap was set the maximum of $2 \mathrm{~mm}$, the pressure drop can be tuned from 130 $\mathrm{KPa}$ to $470 \mathrm{KPa}$. It can be also seen that the maximum pressure drop can be ranged from $470 \mathrm{KPa}$ to $1150 \mathrm{KPa}$ when the applied current was $1.8 \mathrm{~A}$, which satisfied the requirements of improving the resistance forces while not enlarging the valve geometry. Moreover, for each selected resistance gap, the proposed MR valve can work as a conventional MR valve with an annular fluid flow resistance gap. Thus, the proposed MR valve offers a great flexibility in developing valve pressure drops as well as damping forces to some extent. Additionally, this proposed MR vale can work as a bypass valve to control the movement of the cylinder in different loading conditions, which will be 
investigated in our future research.

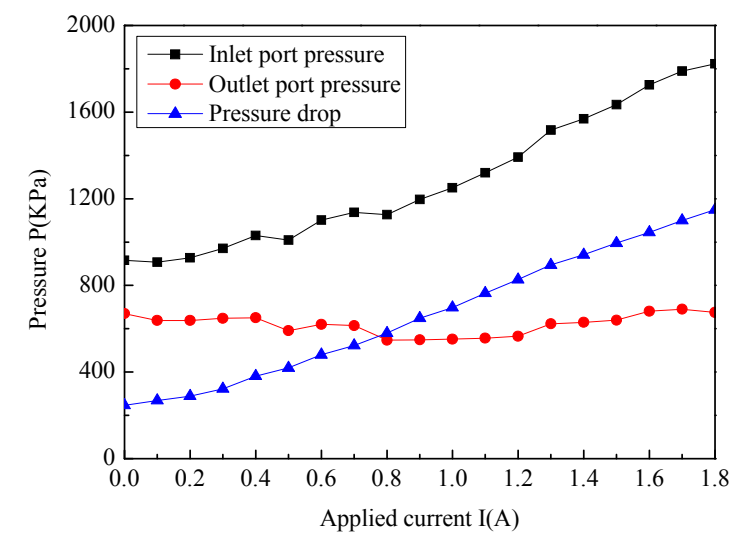

(a)

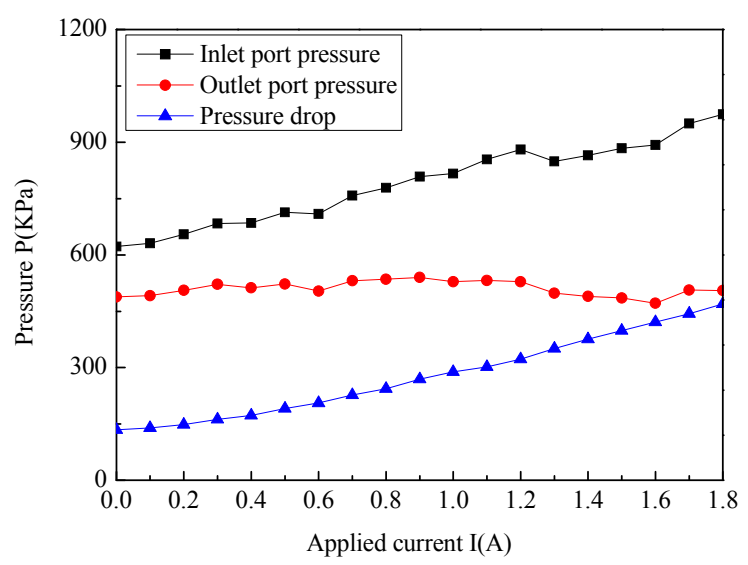

(b)

Figure 16. Pressure drop under continuously applied currents with two typical thicknesses of resistance gap: (a) $\mathrm{h}=1.0 \mathrm{~mm}$ and (b) $\mathrm{h}=2.0 \mathrm{~mm}$

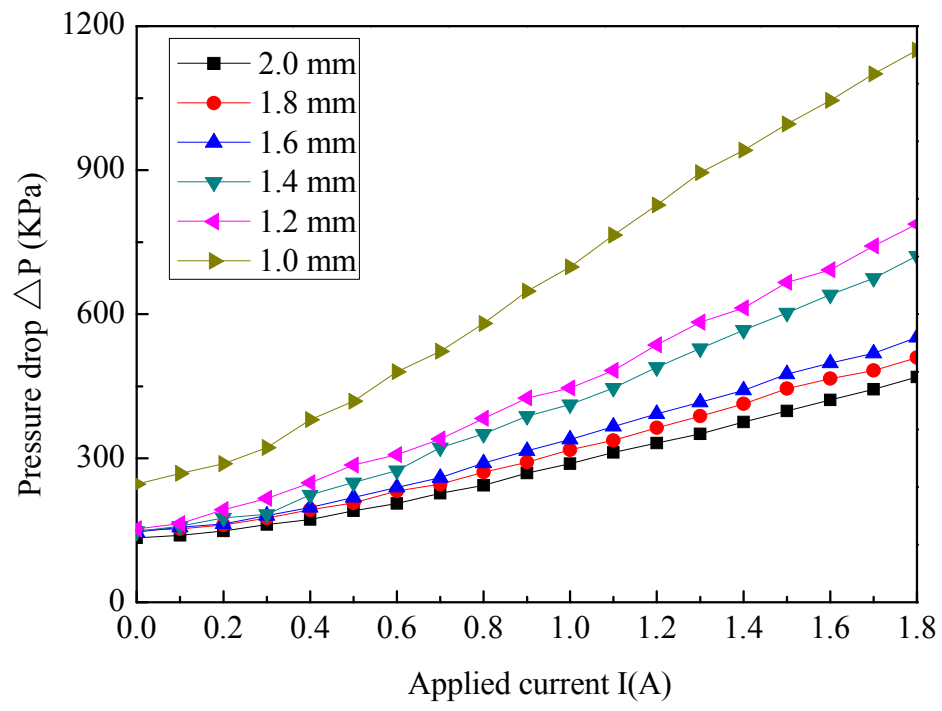

Figure 17. Pressure drop under continuously applied currents with different resistance gaps ( $q=4$ $\mathrm{L} / \mathrm{min}$ )

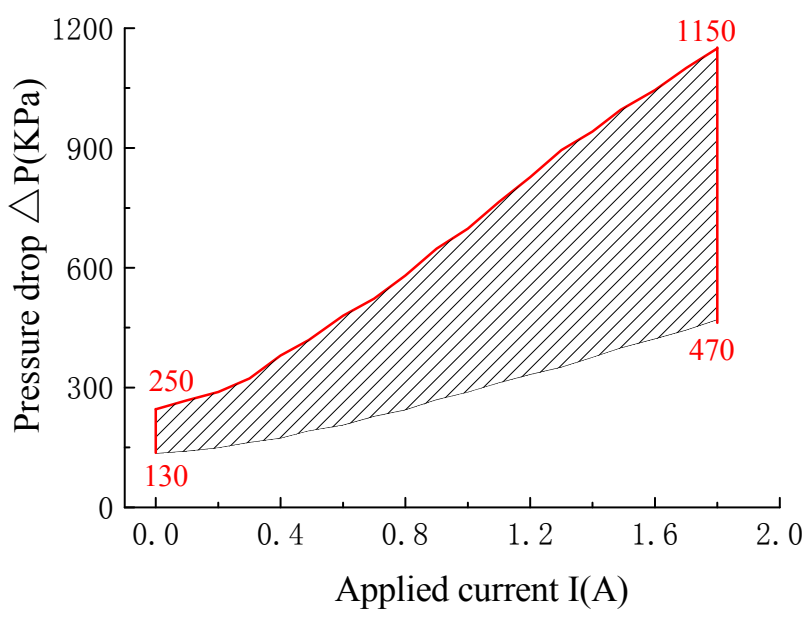

Figure 18. Regulating scope of the pressure drop 
The hysteresis of the MR valve was primarily the result of magnetic hysteresis and fluid dynamics because hysteresis is not necessarily a bad thing. Figure 19 shows the hysteresis of pressure drop under continuously applied currents ranging from $0 \mathrm{~A}$ to $1.8 \mathrm{~A}$, and from $1.8 \mathrm{~A}$ to $0 \mathrm{~A}$ when the resistance gap was $2 \mathrm{~mm}$ wide. In this instance, the percentage of the hysteresis is expressed as the difference between the increasing and decreasing pressure drop divided by the maximum pressure drop. The hysteresis is about $4.5 \%$, which is equivalent to the servo valve used in the hydraulic oil systems.

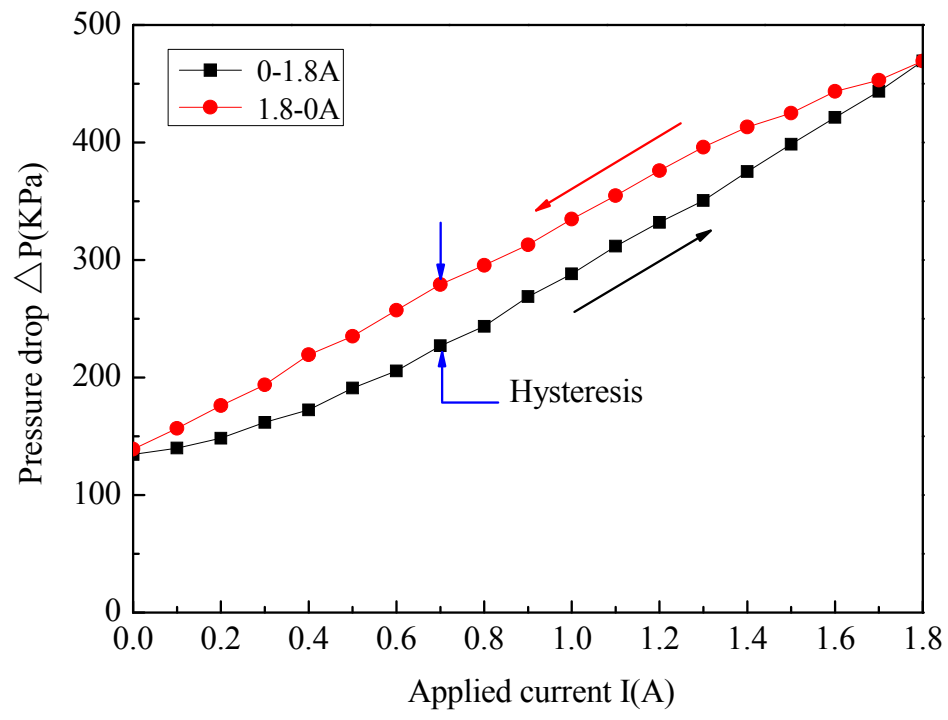

Figure 19. The hysteresis of the pressure drop $(\mathrm{h}=2 \mathrm{~mm})$

\subsubsection{Effect of different loading conditions on the pressure drop}

A relief valve (b) was used in the experimental test rig to simulate the loading conditions in a hydraulic system. Figure 20 shows the variation of pressure drop and loadings under different applied currents when the resistance gap was $2.0 \mathrm{~mm}$ wide. Here the pressure drop remained stable at a certain value when the currents were increased from $0 \mathrm{~A}$ to $1.8 \mathrm{~A}$, which means the loadings do not influence the pressure drop basically. It is also seen that the pressure drop increased as the applied current increased, specifically, the maximum pressure drop can reach $470 \mathrm{KPa}$ when the current was $1.8 \mathrm{~A}$.

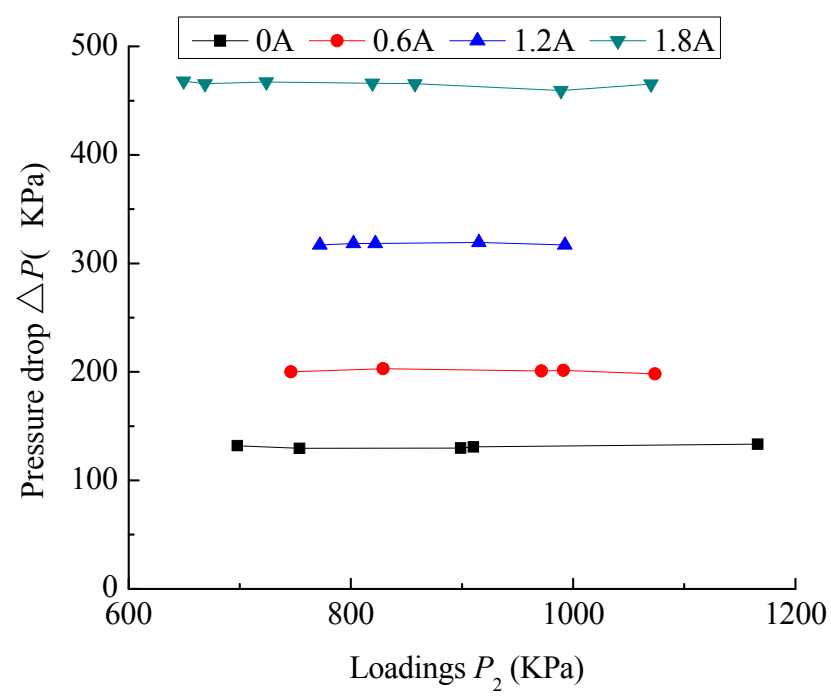

Figure 20. The variation of pressure drop and loadings under different applied currents $(\mathrm{h}=2.0$ $\mathrm{mm})$ 


\section{Conclusions}

In this work a novel MR valve with a tunable resistance gap ranging from $1 \mathrm{~mm}$ to $2 \mathrm{~mm}$ wide was developed. This design is described as an effort to increase the achievable pressure drop of an MR valve without enlarging the size of the valve or increasing its power consumption. This newly proposed MR valve performed better through a finite element analysis, numerical simulations, and experimental test verifications. The pressure drop can vary from $470 \mathrm{KPa}$ to $1150 \mathrm{KPa}$ by tuning the resistance gap and the currents applied to the exciting coil, both of which regulated the pressure in the MR hydraulic system very well.

\section{Acknowledgements}

This research was financially supported by the National Natural Science Foundation of China (Grant No. 51165005, 51475165, 11462004), the International Cooperation Project of Jiangxi Province of China (Grant No. 20132BDH80001), and the University of Wollongong UIC grant.

\section{References:}

[1] M. Mihajlov, V. Nikolic, D. Antic. Position control of an electro-hydraulic servo system. Mechanical Engineering, 2002, 1(9): 1217-1230.

[2] X. Peng, H. Li. Analysis of the magnetomechanical behavior of MRFs based on micromechanics incorporating a statistical approach. Smart Materials and Structures, 2007, 16(6): 2477-2485.

[3] C. R. Liao, D. X. Zhao, L. Xie, Q. Liu. A design methodology for a magnetorheological fluid damper based on a multi-stage radial flow mode. Smart Materials and Structures, 2012, 21(8): 085005.

[4] Grunwald, A. G. Olabi. Design of magneto-rheological (MR) valve. Sensors and Actuators A. 2008, 148: 211-223.

[5] Q. H. Nguyen, S. B. Choi. Optimal design of MR shock absorber and application to vehicle suspension. Smart Materials and Structures, 2009, 18(3): 035012.

[6] X. C. Zhu, X. J. Jing, L. Cheng. Magnetorheological fluid dampers: A review on structure design and analysis. Journal of Intelligent Material Systems and Structures, 2012, 23(8): 839-873.

[7] N. C. Kavlicoglu, B. M Kavlicoglu, Y. M. Liu, C. A. Evrensel, A. Fuchs, G. Korol, F. Gordaninejad. Response time and performance of a high-torque magneto-rheological fluid limited slip differential clutch. Smart Materials and Structures, 2007, 16(1): 149-159.

[8] X. J. Wang, F. Gordaninejad. A new magnetorheological fluid elastomer mount: phenomenological modeling and experimental study. Smart Materials and Structures, 2009, 18(9): 095045.

[9] K. Yoshida1, T. Soga, M. Kawachi, K. Edamura, S. Yokota1. Magnetorheological valve-integrated cylinder and its application. Proceedings of the Institution of Mechanical Engineers, Part I: Journal of Systems and Control Engineering, 2010, 224(1): 31-40.

[10] E. Kostamo, J. Kostamo, J. Kajaste, M. Peitola. Magnetorheological valve in servo applications. Journal of Intelligent Material Systems and Structures, 2012, 23(9): 1001-1010.

[11] N. C. Rosenfeld, N. M. Wereley. Volume-constrained optimization of magnetorheological and electrorheological valves and dampers. Smart Materials and Structures. 2004, 13(6): 1303-1313.

[12] Q. H. Nguyen, Y. M. Han, S. B. Choi, N. M. Wereley. Geometry optimization of MR valves constrained in a specific volume using the finite element method. Smart Materials and Structures. 2007, 16(6): $2242-2252$.

[13] Q. H. Nguyen, S. B. Choi, N. M. Wereley. Optimal design of magnetorheological valves via a finite element 
method considering control energy and a time constant. Smart Materials and Structures, 2008, 17(2): 1-12.

[14] Q. H. Nguyen, S. B. Choi, Y. S. Lee, M. S. Han. An analytical method for optimal design of MR valve structures. Smart Materials and Structures, 2009, 18(9): 1088-1100.

[15] M. Y. Salloom, Z. Samad. Finite element modeling and simulation of proposed design magneto-rheological valve. The International Journal of Advanced Manufacturing Technology, 2011, 54(5-8): 421-429.

[16] M. Y. Salloom, Z. Samad. Magneto-rheological directional control valve. The International Journal of Advanced Manufacturing Technology, 2012, 58(1-4): 279-292.

[17] M. Y. Salloom, Z. Samad. Design and modeling magneto rheological directional control valve. Journal of Intelligent Material Systems and Structures, 2012, 23(2): 155-167.

[18] J. H. Yoo, N. M. Wereley. Design of a high efficiency magnetorheological valve. Journal of Intelligent Material Systems and Structures, 2002, 13(10): 679-685.

[19] J. H. Yoo, N. M. Wereley. Performance of a Magnetorheological Hydraulic Power Actuation System. Journal of Intelligent Material Systems and Structures. 2004, 15(11): 847-858.

[20] J. H. Yoo, J. Sirohi, N. M. Wereley. A magnetorheological piezohydraulic actuator. Journal of Intelligent Material Systems and Structures. 2005, 16(11-12): 945-953.

[21] W. Hu, E. Cook, N. M. Wereley. Energy absorber using a magnetorheological bypass valve filled with ferromagnetic beads. IEEE Transactions on Magnetics, 2007, 43(6): 2695-2697.

[22] W. Hu, R. Robinson, N. M. Wereley. A design strategy for magnetorheological dampers using porous valves. Journal of Physics: Conference Series, 2009, 149(1): 1-4.

[23] F. Gordaninejad, X. Wang, G. Hitchcock, K. Bangrakulur, S. Ruan, M. Siino. Modular high-force seismic magneto-rheological fluid damper. Journal of Structural Engineering, 2010, 135-143.

[24] H. Sahin, F. Gordaninejad, X. J. Wang, Y. M. Liu. Response time of magnetorheological fluids and magneto- rheological valves under various flow conditions. Journal of Intelligent Material Systems and Structures, 2012, 23(9): 949-957.

[25] H. X. Ai, D. H. Wang, W. H. Liao. Design and modeling of a magnetorheological valve with both annular and radial flow paths. Journal of Intelligent Material Systems and Structures, 2006, 17(4): 328-334.

[26] D. H. Wang, H. X. Ai, W. H. Liao. A magnetorheological valve with both annular and radial fluid flow resistance gaps. Smart Materials and Structures, 2009, 18(11): 1-16.

[27] F. Imaduddin, S. A. Mazlan, H. Zamzuri, I. I. M. Yazid. Design and performance analysis of a compact magnetorheological valve with multiple annular and radial gaps. Journal of Intelligent Material Systems and Structures, 2013: 1045389X13508332.

[28] F. Imaduddin, S. A. Mazlan, M. A. A. Rahman, H. Zamzuri, Ubaidillah and B. Ichwan. A high performance magnetorheological valve with a meandering flow path. Smart Materials and Structures, 2014, 23(6): 1-11.

[29] G. L. Hu, L. F. Yu, H. Y. Li , M. Huang, M. Long. Simulation evaluation and performance analysis of a double coil magnetorheological valve. Hydromechatronics Engineering, 2013, 41(18): 11-18.

[30] G. L. Hu, M. Long, M. Huang, W. H. Li. Design, analysis, prototyping, and experimental evaluation of an efficient double coil magnetorheological valve. Advances in Mechanical Engineering, vol. 2014, Article ID 403410, 9 pages, 2014. doi:10.1155/2014/403410.

[31] W. H. Li, H. Du, N. Q. Guo. Finite element analysis and simulation evaluation of a magnetorheological valve. The International Journal of Advanced Manufacturing Technology, 2003, 21(6): 438-445.

[32] J. J. Zheng, Z. C. Li, J. H. Koo, J. Wang. Magnetic circuit design and multiphysics analysis of a novel MR damper for applications under high velocity. Advances in Mechanical Engineering, vol. 2014, Article ID 402501, 16 pages, 2014. doi:10.1155/2014/402501. 